\title{
Invited editorial on "Fissureless fissure-last video-assisted thoracoscopic lobectomy for all lung lobes: a better alternative to decrease the incidence of prolonged air leak?"
}

\author{
Hitoshi Igai, Mitsuhiro Kamiyoshihara, Ryohei Yoshikawa, Fumi Osawa, Tomohiro Yazawa \\ Department of General Thoracic Surgery, Japanese Red Cross Maebashi Hospital, Maebashi, Gunma, Japan \\ Correspondence to: Hitoshi Igai, MD, PhD. 389-1 Asakura-cho, Maebashi, Gunma 371-0811, Japan. Email: hitoshiigai@gmail.com. \\ Provenance: This is an invited Editorial commissioned by the Section Editor Shuang-Jiang Li, MD (Department of Thoracic Surgery and West China \\ Medical Center, West China Hospital, Sichuan University, Chengdu, China). \\ Comment on: Stamenovic D, Bostanci K, Messerschmidt A, et al. Fissureless fissure-last video-assisted thoracoscopic lobectomy for all lung lobes: a \\ better alternative to decrease the incidence of prolonged air leak? Eur J Cardiothorac Surg 2016;50:118-23.
}

Submitted Jun 08, 2018. Accepted for publication Jun 14, 2018.

doi: $10.21037 /$ jtd.2018.06.100

View this article at: http://dx.doi.org/10.21037/jtd.2018.06.100

Thoracic surgeons sometimes have difficulty controlling postoperative air-leakage, particularly in patients with dense fissures. Several studies have shown that prolonged air leak (PAL) is a frequent complication after anatomic pulmonary resections, occurring in $7.6-10 \%$ of all patients with anatomic pulmonary resections (1-4).

To avoid postoperative air leakage, many intraoperative methods have been reported including the use of surgical sealants or stapler line buttress materials $(5,6)$. In addition, several articles have reported that perioperative methods such as digital drainage system or water seal management after a lung lobectomy can reduce the incidence of PAL $(7,8)$. However, none of them has clear benefits or universal applicability.

Lobectomy using fissureless technique was first reported by Temes et al. (9) as a procedure to avoid postoperative PAL, with several other authors subsequently reporting on the efficacy of fissureless lobectomy in terms of reducing the incidence of postoperative PAL (10-14). GómezCaro and colleagues showed that the fissureless technique achieved significant reduction in the incidence and duration of air leakage (13). $\mathrm{Ng}$ and colleagues (12) also showed that the use of a fissureless technique achieved reduction in the duration of chest tube drainage and shortened the length of hospital stay. Most articles about fissureless lobectomy described only right upper lobectomy using fissureless technique because the fissure between a right upper and a middle lobe is more frequently fused compared to other fissures $(11,12)$. However, some articles have reported on the efficacy of fissureless techniques for any type of lobectomy $(13,14)$.

In most studies on fissureless techniques, the approach was via mini-thoracotomy or thoracotomy (11-14). By contrast, Stamenovic et al. (10) used a thoracoscopy with three ports. To the best of our knowledge, that is the only report describing the efficacy of fissureless lobectomy via a thoracoscopic approach except for our previous article (15). Stamenovic et al. prospectively investigated the efficacy of thoracoscopic fissureless lobectomy compared to conventional techniques of dissecting fissure via thoracoscopy. They showed more favorable results in thoracoscopic fissureless lobectomy group compared to conventional lobectomy group about the PAL occurrence rate, the duration of thoracic drainage, and the length of hospital staying (10). It is very important to prove the efficacy of thoracoscopic fissureless lobectomy because the number of patients being treated using the thoracoscopic approach rather than the thoracotomy approach is increasing worldwide. Unfortunately, the authors did not mention whether the thoracoscopic approach is suitable or not for fissureless lobectomy. However, we believe that it might be useful for the fissureless technique compared to a thoracotomy or a mini-thoracotomy approach because it provides a good operative view from various angles without dividing the fissure (16).

Stamenovic et al. also performed pulmonary lobectomies using conventional techniques with a thoracoscopic 
approach over the course of a year. After this period, they performed them using a thoracoscopic fissureless technique. That study had a prospective design, and thus the results were relatively reliable, although it was not a randomized study as the authors insisted. In terms of the possibility that the fissureless group randomly had patients with "better fissure" they denied this possibility based on the fact that the number of staples used for dividing the fissure was larger in the fissureless group (median: 7.5 staples) than in the conventional group (median: 6.5 staples).

In our study, we evaluated the fissural grade in all patients, and a fissureless lobectomy was performed in patients with a fused fissure [fissural grade III or IV as proposed by Craig (17)]. However, Stamenovic et al. did not describe the fissural grade in any patients. In addition, they did not demonstrate the efficacy of fissureless lobectomy in terms of the incidence of postoperative air leakage or PAL in multivariate analyses using a logistic regression model, which might have reduced the impact of their report. However, the robust results of that study are sufficient to justify the efficacy of fissureless lobectomy to avoid postoperative PAL. Moreover, the details of the lobectomy were well described, which can help other thoracic surgeons to perform thoracoscopic fissureless lobectomy appropriately.

Finally, we propose an additional advantage of fissureless lobectomy. When we dissect dense fissures and try to expose the pulmonary artery using conventional techniques, the pulmonary artery is sometimes accidentally injured. Fissureless lobectomy can reduce this possibility, which can lead to safer operations. On the other hand, there is a risk of injuring the pulmonary artery located right behind the lower bronchus when using the fissureless technique to dissect a lower bronchus or divide it using a stapler. Such an injury can lead to catastrophic massive bleeding. To avoid this possibility, the pulmonary arterial sheath is usually dissected enough to proceed through the tissue between the lower bronchus and the pulmonary artery smoothly with forceps or staplers. We consider this dissection critical to avoid this potential major complication.

\section{Acknowledgements}

None.

\section{Footnote}

Conflicts of Interest: The authors have no conflicts of interest to declare.

\section{References}

1. Varela G, Jiménez MF, Novoa N, et al. Estimating hospital costs attributable to prolonged air leak in pulmonary lobectomy. Eur J Cardiothorac Surg 2005;27:329-33.

2. Allen MS, Darling GE, Pechet TT, et al. Morbidity and mortality of major pulmonary resections in patients with early-stage lung cancer: initial results of the randomized, prospective ACOSOG Z0030 trial. Ann Thorac Surg 2006;81:1013-9; discussion 1019-20.

3. Droghetti A, Schiavini A, Muriana P, et al. A prospective randomized trial comparing completion technique of fissures for lobectomy: stapler versus precision dissection and sealant. J Thorac Cardiovasc Surg 2008;136:383-91.

4. Orsini B, Baste JM, Gossot D, et al. Index of prolonged air leak score validation in case of video-assisted thoracoscopic surgery anatomical lung resection: results of a nationwide study based on the French national thoracic database, EPITHOR. Eur J Cardiothorac Surg 2015;48:608-11.

5. Miller JI Jr, Landreneau RJ, Wright CE, et al. A comparative study of buttressed versus nonbuttressed staple line in pulmonary resections. Ann Thorac Surg 2001;71:319-22; discussion 323.

6. Anger WH Jr. Surgical sealant for preventing air leaks after pulmonary resections in patients with lung cancer. AORN J 2010;92:351-2.

7. Brunelli A, Sabbatini A, Xiume' F, et al. Alternate suction reduces prolonged air leak after pulmonary lobectomy: a randomized comparison versus water seal. Ann Thorac Surg 2005;80:1052-5.

8. Filosso PL, Nigra VA, Lanza G, et al. Digital versus traditional air leak evaluation after elective pulmonary resection: a prospective and comparative monoinstitutional study. J Thorac Dis 2015;7:1719-24.

9. Temes RT, Willms CD, Endara SA, et al. Fissureless lobectomy. Ann Thorac Surg 1998;65:282-4.

10. Stamenovic D, Bostanci K, Messerschmidt A, et al. Fissureless fissure-last video-assisted thoracoscopic lobectomy for all lung lobes: a better alternative to decrease the incidence of prolonged air leak? Eur J Cardiothorac Surg 2016;50:118-23.

11. Refai M, Brunelli A, Salati M, et al. Efficacy of anterior fissureless technique for right upper lobectomies: a casematched nalysis. Eur J Cardiothorac Surg 2011;39:1043-6.

12. Ng T, Ryder BA, Machan JT, et al. Decreasing the incidence of prolonged air leak after right upper lobectomy with the anterior fissureless technique. J Thorac Cardiovasc Surg 2010;139:1007-11. 
13. Gómez-Caro A, Calvo MJ, Lanzas JT, et al. The approach of fused fissures with fissureless technique decreases the incidence of persistent air leak after lobectomy. Eur J Cardiothorac Surg 2007;31:203-8.

14. Nomori H, Ohtsuka T, Horio H, et al. Thoracoscopic lobectomy for lung cancer with a largely fused fissure. Chest 2003;123:619-22.

15. Igai H, Kamiyoshihara M, Yoshikawa R, et al. The efficacy of thoracoscopic fissureless lobectomy in patients with dense fissures. J Thorac Dis 2016;8:3691-6.

16. Igai H, Kamiyoshihara M, Kawatani N, et al. Thoracoscopic caudal left lower lobectomy in a patient with fused fissure. Asian J Endosc Surg 2014;7:342-4.

17. Craig SR, Walker WS. A proposed anatomical classification of the pulmonary fissures. J R Coll Surg Edinb 1997;42:233-4.

Cite this article as: Igai $\mathrm{H}$, Kamiyoshihara M, Yoshikawa R, Osawa F, Yazawa T. Invited editorial on "Fissureless fissurelast video-assisted thoracoscopic lobectomy for all lung lobes: a better alternative to decrease the incidence of prolonged air leak?”. J Thorac Dis 2018;10(Suppl 18):S2183-S2185. doi: 10.21037/jtd.2018.06.100 